\title{
Article \\ Demulsification Behavior of Alkali and Organic Acid in Zinc Extraction
}

\author{
Tao Jiang, Feiyu Meng, Ke Li, Qaing Zhong *, Bin Xu, Qian Li and Yongbin Yang *
}

check for updates

Citation: Jiang, T.; Meng, F.; Li, K.; Zhong, Q.; Xu, B.; Li, Q.; Yang, Y.

Demulsification Behavior of Alkali and Organic Acid in Zinc Extraction. Metals 2021, 11, 1833. https:// doi.org/10.3390/met11111833

Academic Editors: Petros E. Tsakiridis and Fernando Castro

Received: 12 September 2021 Accepted: 2 November 2021 Published: 15 November 2021

Publisher's Note: MDPI stays neutral with regard to jurisdictional claims in published maps and institutional affiliations.

Copyright: (c) 2021 by the authors. Licensee MDPI, Basel, Switzerland. This article is an open access article distributed under the terms and conditions of the Creative Commons Attribution (CC BY) license (https:// creativecommons.org/licenses/by/ $4.0 /)$.
School of Minerals Processing and Bioengineering, Central South University, Changsha 410083, China; jiangtao@csu.edu.cn (T.J.); mengfeiyu@csu.edu.cn (F.M.); like018@csu.edu.cn (K.L.); xuandy_16@csu.edu.cn (B.X.); csuliqian@csu.edu.cn (Q.L.)

* Correspondence: zhongqiang@csu.edu.cn (Q.Z.); yangyongbin@csu.edu.cn (Y.Y.); Tel.: +86-731-8883-0547 (Y.Y.)

\begin{abstract}
Alkali agents could be used to enhance the extraction of zinc from solution of high concentration, but excess alkali can sensitively lead to emulsification of the solution. In this paper, the emulsification in the extraction process, demulsification, and extraction with different additives and its action mechanism were studied. The results indicate that the associated addition of alkali and organic acid could eliminate emulsification and improve zinc extraction. The extraction ratio of zinc reached $99.61 \%$ under the conditions of $104 \mathrm{~mL} / \mathrm{L}$ organic acid, $80 \mathrm{~g} / \mathrm{L}$ alkali, and $40 \%$ extractant concentration. Zinc hydroxide formed from hydroxyl and zinc ion at sensitively increased $\mathrm{pH}$ was the cause of emulsification during extraction. Associated addition of alkali and organic acid could contribute to the control solution $\mathrm{pH}$ in the range of 3.0-4.0, which is lower than that of the formation of zinc hydroxide, and therefore, improve zinc extraction.
\end{abstract}

Keywords: demulsification; zinc extraction; saponification pre-treatment; alkali and organic acid; zinc hydroxide

\section{Introduction}

As an important separation method that is widely applied in many industries such as petrochemical, pharmaceutical, and hydrometallurgical, solvent extraction has quite a few favourable advantages for separation and recovery of valuable metals from solutions [1-3]. Accordingly, it is commonly used for separating and concentrating for metals such as zinc, copper, nickel, cobalt, uranium, and other metal ions [4]. In hydrometallurgy, several extraction methods including cationic extraction [5-7], neutral extraction [8,9], anions extraction $[10,11]$, and synergistic extraction $[12,13]$ have been reported. As for zinc, which is usually in the form of sulfate in solutions and occurring as $\mathrm{Zn}^{2+}$, cationic extraction has been widely considered to be most suitable because of its high selectivity.

Recently, some phosphorus extractants such as D2EHPA, TBP, and Cyanex272 have been marketed and applied extensively in extraction technology [14-16]. Among them, the most common reagent is D2EHPA. The general reaction for the extraction by an organophosphorus acid is displayed in Equation (1).

$$
\mathrm{M}^{x+}+n(\mathrm{RH})_{m} \rightarrow \mathrm{MR}_{x}(\mathrm{RH})_{n m-x}+x \mathrm{H}^{+}
$$

where $\mathrm{M}^{x+}$ is the metal cation, $\mathrm{RH}$ is the extractant, and $m$ is the association degree of extractant. For the extraction of zinc sulfate with D2EHPA, $n=1.5$ and $m$ depend on the diluent ( $m=1$ for aromatic and $m=2$ for aliphatic [17]).

A hydrometallurgical treatment on the recovery of zinc from a low concentration leachate zinc extraction with D2EHPA (di-2-ethylhexyl phosphoric acid) has been studied by Vahidi et al., in which the operation variables such as $\mathrm{pH}$, D2EHPA concentration, temperature, aqueous/organic $(\mathrm{A} / \mathrm{O})$ phase ratio, tri-butyl phosphate $(\mathrm{TBP})$ concentration, and sodium sulfate concentration have been considered. The result demonstrated that all zinc 
was extracted from the aqueous solution at $\mathrm{pH} 2.5$ with $20 \% w / w$ D2EHPA concentration in kerosene $[18,19]$. Zinc was preferentially extracted with D2EHPA at low pH (below 2.5) and in a short time $(5 \mathrm{~min})$. The continuous operation containing three extraction stages and three stripping stages, operated in a counter-current manner, has demonstrated that zinc could be removed quantitatively and selectively from the effluent (overall efficiency higher than 98\%). Chen et al. studied zinc extraction using the D2EHPA reagent from zinc containing a low acid waste solution [20]. The result demonstrated that zinc can be efficiently extracted, and zinc concentration in the solution was reduced from $2.2 \mathrm{~g} / \mathrm{L}$ to $0.003 \mathrm{~g} / \mathrm{L}$.

In the process of zinc extraction with D2EHPA, the extraction reaction is greatly influenced by the $\mathrm{pH}$ value of solution, while the substitution of hydrogen ions may lead to a decrease in $\mathrm{pH}$. For solutions of low zinc, the $\mathrm{pH}$ decrease may not be so noticeable as to affect the extraction [21]. However, for high zinc solutions, the $\mathrm{pH}$ decrease is so marked that the zinc extraction equilibrium is substantially influenced, which significantly reduces zinc extraction ratio. Therefore, extraction of zinc in high concentration solutions should be accompanied by control of $\mathrm{pH}$ to ensure high extraction recovery. However, direct addition of common alkali reagents may cause sensitive reaction to the solution $\mathrm{pH}$ so that a quick $\mathrm{pH}$ increase usually, uncontrollably, takes place, leading to emulsification, which destroys the phase separation.

According to the literature [22], the causes for emulsification could be divided into two categories. One is the generation of surfactants, the other is the generation of precipitates. Both of them reduce the interfacial tension and lead to emulsification. In zinc extraction, the generation of precipitates at unfavorably higher $\mathrm{pH}$, mainly hydroxides, turns out to be the main cause for emulsification. When zinc extraction is conducted to solutions with relatively low concentration, a certain saponification treatment could be applied to avoid emulsification and achieve a good extraction ratio [11]. However, in cases of higher zinc concentration, the emulsification cannot be effectively controlled by only applying a saponification treatment.

This paper focus on the emulsification in zinc extraction with D2EHPA extractant from solutions with zinc up to $30 \mathrm{~g} / \mathrm{L}$. Demulsification techniques were studied to eliminate the emulsification so as to intensify the zinc extraction.

\section{Materials and Methods}

\subsection{Materials and Reagents}

The chemical reagents in the aqueous phase such as zinc sulfate, ammonium hydroxide, glacial acetic acid, and sodium hydroxide are all of analytical reagent grade, and were provided by Guangzhou luyuan Chemical and Glass Instrument Co. Ltd., Guangzhou, China. The extractant bis(2-ethylhexyl) thiophosphoric acid (D2EHPA) was supplied by Zhengzhou Qinshi Technologies Co. Ltd., Zhengzhou, China, and used without further purification. The extractant was dissolved in sulfonated kerosene provided by Shenzhen Yishun Petrochemical industry Co. Ltd., Shenzhen, China. After dilution, the organic phase was washed with deionized water to remove the soluble impurities. Redistilled water prepared by a water purification system (UPR-I-5/10/15T, Wuhan Youpu Instrument Co., LTD, Wuhan, China) was used throughout all experiments.

\subsection{Experimental Methods}

\subsubsection{Extraction Tests}

The extraction tests were carried out at the temperature of $25 \pm 0.5^{\circ} \mathrm{C}$ with an aqueous: organic (A:O) ratio of 1:1. The two phases were mixed with mechanical agitation for $10 \mathrm{~min}$. Then, put it in a separating funnel and kept stationary for $3 \mathrm{~min}$ to induce the phase separation. The content of zinc and $\mathrm{pH}$ value in the aqueous phase were determined. 


\subsubsection{Saponification Test}

The organic phase and a certain amount of saponifier solution was placed in a beaker, and the solution was stirred at $200 \mathrm{rpm}$ for a certain time. Unless otherwise stated, all the experiments were carried out at $25 \pm 0.5^{\circ} \mathrm{C}$ by heating in an external water bath After the experiment was finished, the solution was placed in a separating funnel, and kept stationary for $8 \mathrm{~min}$ to separate the aqueous phase and organic phase. The volume of aqueous phase and organic phase was measured, and the concentration of $\mathrm{Zn}$ in the aqueous phase was also analyzed to determine the saponification ratio. The organic phase was used in the subsequent experiments.

\subsection{Analytical Method}

The concentration of zinc in aqueous solutions, after coming into contact with the organic extractant, were analyzed using inductively coupled plasma-atomic adsorption spectrometry (PS-6, Barid; Milwaukee, WI, USA). The $\mathrm{pH}$ values of solution were measured with a $\mathrm{pH}$ mater (PHSJ-4A). The extracted amounts from the organic extractants were calculated through the concentration differences in the aqueous solutions before and after extraction. The organic matter and emulsion were analyzed by a Fourier Transform Infrared Spectrometer (IRAffinity-1, Bruker; Billerica, MA, USA).

The saturation capacity represents the maximum load that the system can carry in stable conditions. Thus, it is necessary to study the saturation capacity of extractant for the purpose of extraction process. The saturation capacity of extractant was determined under the conditions of $\mathrm{Zn}(\mathrm{II})$ concentration $8 \mathrm{~g} / \mathrm{L}$, initial $\mathrm{pH}$ 3.0, A/O ratio 50:50, stirring speed $1000 \mathrm{rpm}$, and extraction time $15 \mathrm{~min}$. After being stationary for $10 \mathrm{~min}$, the organic phase and raffinate was separated, and the concentration of zinc in the raffinate was also determined. Then, the organic phase was mixed with a fresh solution containing zinc for extraction, phase separation, and detection. The extraction of zinc was repeated several times until the concentration of zinc ions in the raffinate remained unchanged, and the organic phase was considered to reach saturation.

\section{Results and Discussion}

\subsection{Zinc Extraction with D2EHPA Extractant}

The effect of zinc concentration on zinc extraction with D2EHPA extractant was studied under the conditions of 20\% D2EHPA, $\mathrm{pH} 3.0$, O/A ratio 50:50, $1000 \mathrm{rpm}$, and $10 \mathrm{~min}$. As the results demonstrate in Figure 1, zinc extraction ratio decreased with zinc concentration increase in the range of $2-15 \mathrm{~g} / \mathrm{L}$, due to the inevitably noticeable decrease of solution $\mathrm{pH}$. When zinc concentration was higher than $15 \mathrm{~g} / \mathrm{L}$, the $\mathrm{pH}$ of raffinate remained unchanged, while the extraction of zinc kept decreasing. Such a change in $\mathrm{pH}$ indicated that no more hydrogen ion is substituted into the solution at zinc concentrations above $15 \mathrm{~g} / \mathrm{L}$, demonstrating that the further extraction of zinc did not take place because of the saturation of zinc in the oil phase. Accordingly, the decrease of the extraction ratio was only due to the increase of total zinc quantity in the solutions.

As reported in the literature [21], the equilibrium partition ratio is related to the $\mathrm{pH}$ value, and the equilibrium partition ratio is higher at higher $\mathrm{pH}$. The more zinc in initial solutions, the more hydrogen ions substituted, and a lower $\mathrm{pH}$ value as well as a lower extraction ratio resulted. Therefore, the prevention of $\mathrm{pH}$ decrease by substituting hydrogen ions plays a key role in ensuring high zinc extraction. In cases of higher zinc solution, development of effective techniques to control solution $\mathrm{pH}$ is of great significance.

As calculated, $\mathrm{Zn}$ (II) can be precipitated to $\mathrm{Zn}(\mathrm{OH})_{2}$ at $\mathrm{pH}$ 6.0, and thus, the maximum amount of alkali without precipitation of $\mathrm{Zn}(\mathrm{OH})_{2}$ is $45 \mathrm{~g} / \mathrm{L}$ in a solution of $30 \mathrm{~g} / \mathrm{L}$ zinc. In order to adjust the $\mathrm{pH}$ of raffinate, zinc extraction with the addition of alkali $\mathrm{NaOH}$ was carried out, and the results are displayed in Table 1. With the dosage of alkali increased from $0 \mathrm{~g} / \mathrm{L}$ to $19.2 \mathrm{~g} / \mathrm{L}$, the $\mathrm{pH}$ value of raffinate increased slowly up to 2.5 , and zinc extraction accordingly increased. However, with the alkali dosage further increased to above $24 \mathrm{~g} / \mathrm{L}$, the $\mathrm{pH}$ increase became quicker and ultimately uncontrollable. Although 
the equilibrium ratio still increased, emulsification appeared, and phase separation was badly impacted. Therefore, the direct addition of common alkali sodium hydroxide may cause a sensitive reaction and an uncontrollable increase to the solution $\mathrm{pH}$; alternative methods for $\mathrm{pH}$ control are urgently needed.

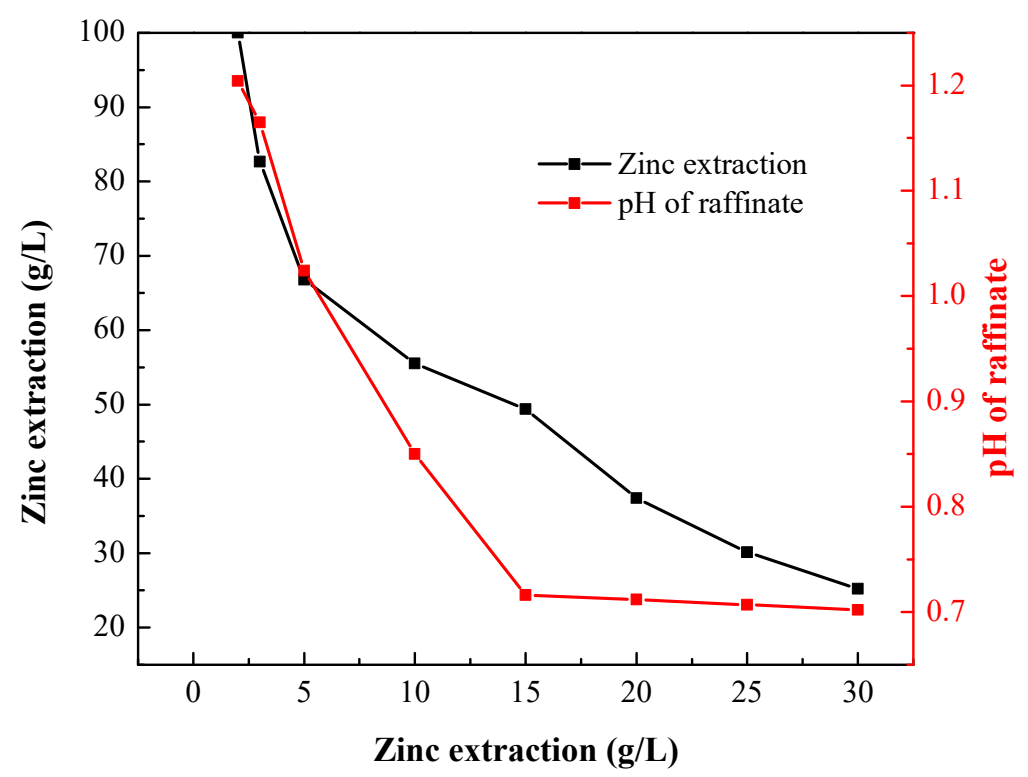

Figure 1. The effect of zinc concentration on zinc extraction. Conditions: initial pH 3.0, D2EHPA concentration $20 \%$, O/A ratio 50:50, stirring speed $1000 \mathrm{rpm}$, and time $10 \mathrm{~min}$.

Table 1. Effect of alkali dosage on zinc extraction from a zinc concentration of $30 \mathrm{~g} / \mathrm{L}$ solution.

\begin{tabular}{cccc}
\hline Alkali Dosage (g/L) & Extraction (\%) & pH Value of Raffinate & Extraction Phenomenon \\
\hline 0 & 23.92 & 1.334 & - \\
4.8 & 30.85 & 1.491 & - \\
9.6 & 37.95 & 1.711 & - \\
14.4 & 44.71 & 2.018 & - \\
19.2 & 53.47 & 2.511 & emulsification \\
24 & 56.08 & 3.240 & emulsification \\
28 & 65.78 & 6.555 & emulsification \\
\hline
\end{tabular}

\subsection{Demulsification}

3.2.1. Demulsification by Saponification Pre-Treatment of Extractant

In order to prevent the sensitive quick increase of solution $\mathrm{pH}$, the organic phase with extractant D2EHPA was pretreated by saponification. The experiments were performed under the condition of 20\% D2EHPA, $\mathrm{pH} 3.0, \mathrm{O} / \mathrm{A}$ ratio 50:50, $1000 \mathrm{rpm}$, and $10 \mathrm{~min}$. The effect of alkali dosage on extractant saponification and zinc extraction are displayed in Table 2. It was found that emulsification could be alleviated to some extent by a saponification pre-treatment of the extractant. The emulsification caused by the direction addition of alkali at $24 \mathrm{~g} / \mathrm{L}$ did not appear at the same dosage of alkali by saponification. However, at a higher dosage of alkali, such as $28 \mathrm{~g} / \mathrm{L}$, emulsification appeared again. Although the saponification pre-treatment of extractant could not entirely avoid emulsification, it allows more addition of alkali. Therefore, a saponification pre-treatment of extractant can be applied for demulsification in cases of zinc extraction at lower concentrations whose alkali addition for $\mathrm{pH}$ control are no more than $24 \mathrm{~g} / \mathrm{L}$, but for higher zinc concentrations, further demulsification measures are desired. 
Table 2. The effect of alkali dosage on the saponification of extractant and zinc extraction.

\begin{tabular}{ccccc}
\hline Alkali Dosage (g/L) & Saponification Ratio (\%) & Extraction (\%) & The pH of Raffinate & Extraction Phenomenon \\
\hline 0 & 0 & 23.92 & 1.334 & - \\
4.8 & 20 & 30.16 & 1.534 & - \\
9.6 & 40 & 36.07 & 1.719 & - \\
14.4 & 60 & 41.51 & 2.012 & - \\
19.2 & 80 & 50.19 & 2.548 & - \\
24 & 100 & 57.47 & 3.082 & - \\
28 & 100 & 60.40 & 5.573 & emulsification \\
32 & 100 & 61.87 & 6.087 & emulsification \\
\hline
\end{tabular}

\subsubsection{Demulsification by Addition of Sodium Salt of Organic Acid}

For further demulsification in cases of higher zinc concentration, the addition of sodium salt of organic acid was studied in addition to the saponification pre-treatment of extractant. The experiments of demulsification were carried out under the conditions of $20 \%$ D2EHPA, 3.0 M NaOH, saponification ratio of $80 \%$, and saponification time $8 \mathrm{~min}$. Accordingly, zinc extraction experiments at $30 \mathrm{~g} / \mathrm{L}$ were carried out to evaluate the effect of demulsification on zinc extraction.

As displayed in Figure 2, a demulsification effect was favorably attained and the demulsified ratio increased as sodium salt of organic acid dosage increased in its initial stage of $0-8 \mathrm{~g} / \mathrm{L}$; afterward, it was roughly steady. In addition, Table 3 indicates that, with the increase of sodium salt of organic acid after saponification, demulsification was attained even at a high alkali dosage of $32 \mathrm{~g} / \mathrm{L}$ and the extraction ratios were increased compared to Table 2.

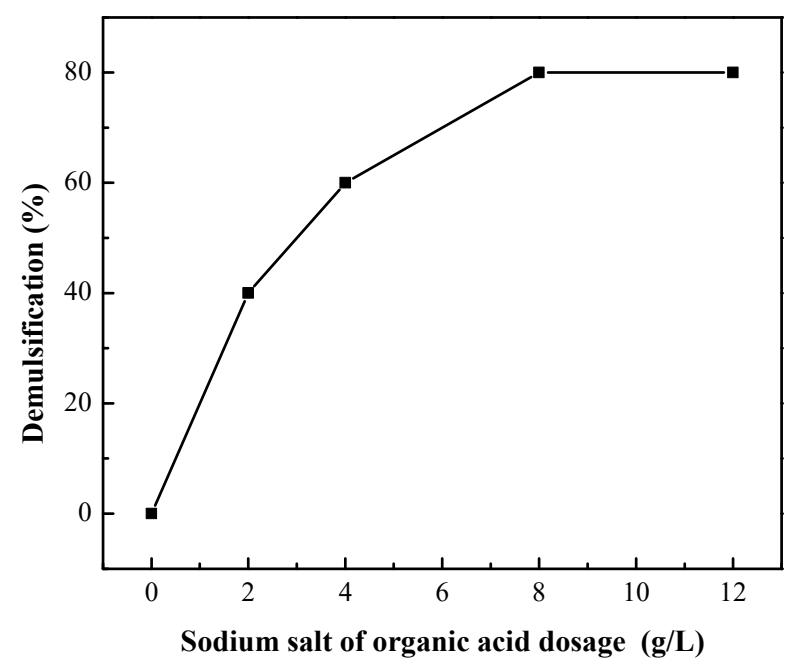

Figure 2. The relationship between the content of a salt compounded with alkali and weak acid and the ratio of demulsification (Conditions: 20\% D2EHPA extractant, $3 \mathrm{M} \mathrm{NaOH}, 80 \%$ saponification ratio, and time $8 \mathrm{~min}$ ).

Table 3. The extraction of zinc after saponification pre-treatment and demulsification.

\begin{tabular}{cccccc}
\hline Alkali Dosage (g/L) & Saponification Ratio (\%) & Salt Dosage (g/L) & Demulsification Ratio (\%) & Extraction (\%) & pH of Raffinate \\
\hline 19.2 & 80 & 8 & 80 & 54.40 & 2.636 \\
24 & 100 & 10 & 70 & 60.12 & 3.641 \\
28 & - & 12 & 50 & 63.90 & 6.428 \\
32 & - & 13 & 50 & 63.96 & 6.672 \\
\hline
\end{tabular}

The sodium salt of organic acid that is made of alkali and a weak organic acid served to stabilize the solution $\mathrm{pH}$ by combining the substituted hydrogen ions during zinc extraction, 
which allowed a lower dosage of alkali in saponification so that the emulsification was favorably alleviated.

\subsection{Zinc Extraction with D2EHPA by Direct Addition of Alkali and Organic Acid}

As above mentioned, zinc extraction was badly influenced by emulsification, and demulsification could be favorably attained by the saponification pre-treatment of extractant in association with the addition of alkali salt of a week organic acid. Since both saponification and the salt additive involved the use of alkali sodium hydroxide and the addition of organic acid had a marked effect on demulsification, it is reasonable to infer that the main effect on demulsification was the associated performance of alkali and organic acid. Based on this idea, the direct extraction of zinc without extractant saponification by the simultaneous addition of alkali and organic acid was studied.

\subsubsection{Effect of Organic Acid Dosage}

Table 4 displays the effect of acid dosage on zinc extraction at the alkali dosage of $40 \mathrm{~g} / \mathrm{L}$ under the conditions of 20\% D2EHPA, $\mathrm{pH} 3.0$, O/A ratio 50:50, extraction time $10 \mathrm{~min}$, phase separation time $3 \mathrm{~min}$, and $1000 \mathrm{rpm}$. When acid dosage was lower than $52 \mathrm{~mL} / \mathrm{L}$, emulsification appeared in the extraction. As the results demonstrate, at the alkali dosage of $40 \mathrm{~g} / \mathrm{L}$, when organic acid dosage increased above $52 \mathrm{~mL} / \mathrm{L}$, emulsification in the extraction process was avoided and the extraction was accomplished. Meanwhile, a zinc extraction ratio decrease was observed with an increase in organic acid above $52 \mathrm{~mL} / \mathrm{L}$, which could be attributed to the decrease of $\mathrm{pH}$. The increase of extraction ratio should be increased by further optimization of other factors.

Table 4. The effect of acid dosage on zinc extraction at alkali dosage of $40 \mathrm{~g} / \mathrm{L}$.

\begin{tabular}{cccc}
\hline Organic Acid Dosage (mL/L). & Extraction (\%) & pH of Raffinate & Extraction Phenomenon \\
\hline 20 & - & - & emulsification \\
40 & - & - & emulsification \\
52 & 61.79 & 3.063 & - \\
100 & 56.00 & 2.935 & - \\
\hline
\end{tabular}

\subsubsection{Effect of Alkali Dosage}

In Table 5, the effect of alkali dosage on zinc extraction is presented at an acid dosage of $52 \mathrm{~mL} / \mathrm{L}$. It is apparent that raffinate $\mathrm{pH}$ and zinc extraction went up when alkali dosage increased in the range of 8-40 g/L. It indicates that the dosage of alkali exceeds the range of organic acid to adjust the $\mathrm{pH}$ value, and emulsification will appear, while emulsification occurred at the alkali dosage above $40 \mathrm{~g} / \mathrm{L}$. Therefore, weak acid with $52 \mathrm{~mL} / \mathrm{L}$ and alkali with $40 \mathrm{~g} / \mathrm{L}$ are the best dosage for zinc extraction.

Table 5. The effect of alkali dosage on zinc extraction at acid dosage at $52 \mathrm{~mL} / \mathrm{L}$.

\begin{tabular}{cccc}
\hline Alkali Dosage (g/L) & Extraction (\%) & pH of Raffinate & Extraction Phenomenon \\
\hline 8 & 34.32 & 2.013 & - \\
24 & 52.48 & 2.793 & - \\
32 & 55.18 & 2.902 & - \\
40 & 61.79 & 3.063 & emulsification \\
\hline
\end{tabular}

\subsubsection{Effect of Extractant Concentration}

It is noticed that, as mentioned above, zinc extraction ratios were all at relatively low levels. Since those experiments were conducted at a low extractant concentration, the low zinc extraction ratios could be considered to be limited by the capacity of the 
extractant. Therefore, a higher extractant concentration could be expected to increase the extraction ratio.

The effect of extractant concentration on zinc extraction is displayed in Table 6; with the increase of extractant concentration, the zinc extraction ratio was significantly raised. Under the condition of $40 \%$ extractant concentration, $104 \mathrm{~mL} / \mathrm{L}$ organic acid, and $80 \mathrm{~g} / \mathrm{L}$ alkali, the zinc extraction ratio reached $99.61 \%$, demonstrating that the zinc in the solution was almost entirely extracted. Nevertheless, the direct extraction of zinc by simultaneous direct addition of alkali and organic acid perfectly stabilized solution $\mathrm{pH}$ without emulsification, which effectively ensured a high extraction ratio at high zinc concentrations up to $30 \mathrm{~g} / \mathrm{L}$.

Table 6. The effect of D2EHPA extractant concentration on zinc extraction.

\begin{tabular}{|c|c|c|c|c|}
\hline Extractant $(\%)$ & Alkali Dosage (g/L) & Organic Acid Dosage (mL/L) & Extraction \% & $\mathrm{pH}$ of Raffinate \\
\hline \multirow{3}{*}{20} & 40 & 52 & 61.79 & 3.063 \\
\hline & 48 & 64 & 61.93 & 3.188 \\
\hline & 56 & 76 & 62.62 & 3.298 \\
\hline \multirow{3}{*}{30} & 40 & 52 & 79.39 & 2.692 \\
\hline & 56 & 72 & 86.88 & 3.159 \\
\hline & 64 & 84 & 87.64 & 3.287 \\
\hline \multirow{4}{*}{40} & 40 & 52 & 91.34 & 2.350 \\
\hline & 48 & 64 & 96.64 & 2.770 \\
\hline & 64 & 84 & 98.29 & 3.242 \\
\hline & 80 & 104 & 99.61 & 3.370 \\
\hline
\end{tabular}

\subsection{Mechanism of Intensified Extraction with Associated Additives of Alkali and Organic Acid}

\subsubsection{Saturation Capacity}

The saturation capacity of an extractant with and without the addition of alkali and organic acid have been investigated, and the results are displayed in Figure 3. Apparently, the saturation capacity of an extractant increased with the increase of the extractant concentration, and the saturation capacity had a linear relationship with the extractant concentration. Besides, the saturation capacity of the extractant with the addition of alkali and organic acid is relatively higher than that without additives; this indicates that the addition of alkali and weak acid could not only adjust the solution $\mathrm{pH}$, but also improve the saturation capacity of the extractant.

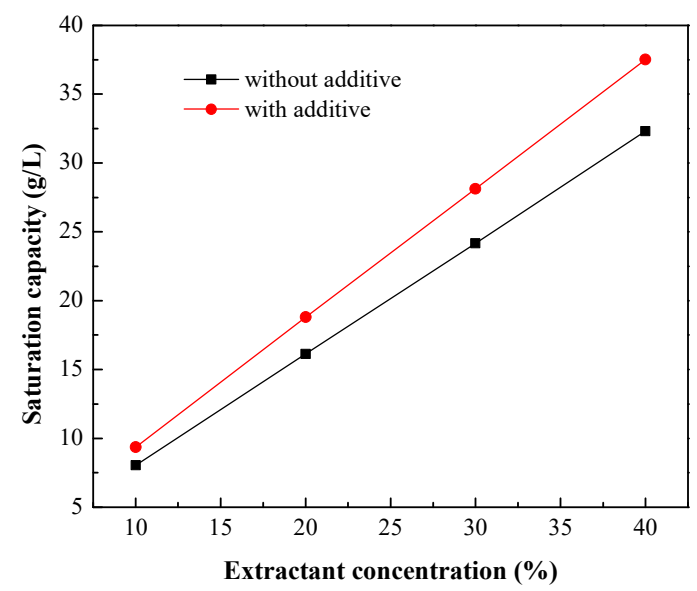

Figure 3. The saturation capacity of an extractant with and without the compound additive of organic acid and strong alkali (Conditions: zinc concentration $8 \mathrm{~g} / \mathrm{L}$, initial $\mathrm{pH}$ 3.0, A/O ratio 50:50, stirring speed $1000 \mathrm{rpm}$, and extraction time $15 \mathrm{~min})$. 


\subsubsection{FTIR Spectroscopy}

The FTIR spectroscopies of the organic phase without and with addition of alkali and organic acid are in Figure 4a,b, respectively. It is clear from Figure 4a that the peak of P-O-H bond in the D2EHPA extractant disappeared, which indicated that the hydrogen bond in D2EHPA was completely broken, and the $\mathrm{P}=\mathrm{O}$ bond was not associated with the hydrogen bond in D2EHPA after extraction. The peak of the $\mathrm{P}=\mathrm{O}$ bond shifted to $1197.58 \mathrm{~cm}^{-1}$ and demonstrated that $\mathrm{P}=\mathrm{O}$ still existed in the form of an associative, and the bond energy of $\mathrm{P}=\mathrm{O}$ was weakened. After extraction, the zinc ions could associate with the $\mathrm{P}=\mathrm{O}$ bond in the organic phase. The peak of the $\mathrm{C}-\mathrm{O}$ bond was moved to $1105.01 \mathrm{~cm}^{-1}$ due to the coordination of the $\mathrm{P}=\mathrm{O}$ bond with the zinc ion [23-25]. For the addition of alkali and organic acid, the peak of $\mathrm{P}-\mathrm{O}-\mathrm{H}$ bond still existed, and the peak of $\mathrm{P}=\mathrm{O}$ was transferred to $1205.49 \mathrm{~cm}^{-1}$. Furthermore, the vibration absorption peak of organic acid appeared at $1634.92 \mathrm{~cm}^{-1}$, and it indicated that organic acid salts appeared in the organic phase after extraction.
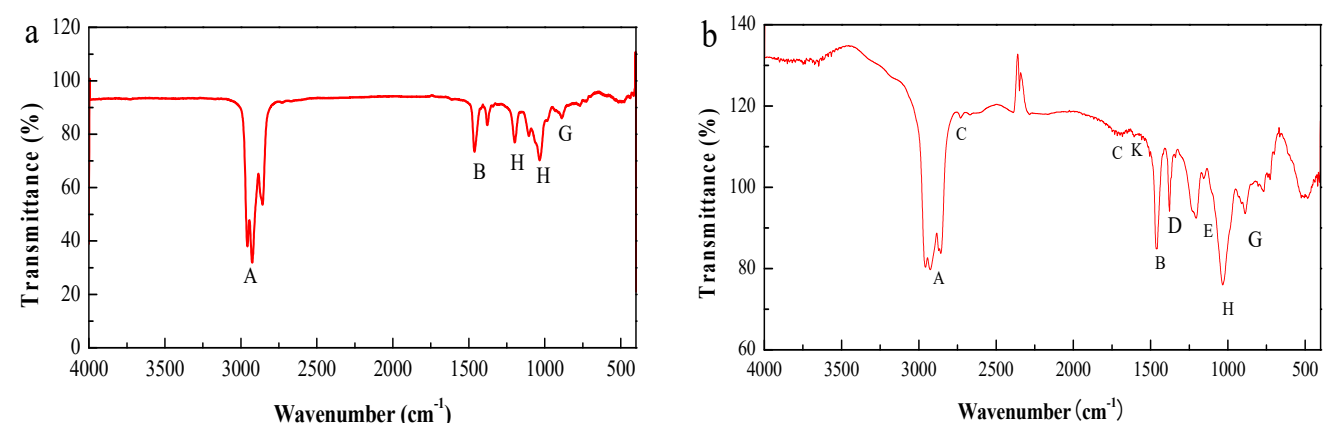

Figure 4. The FTIR spectroscopy for organic phase: (a) without addition of organic acid and strong alkali, and (b) with addition of organic acid and alkali. A, stretching vibration of $\mathrm{C}-\mathrm{H}$; $\mathrm{B}$, bending vibration of $\mathrm{C}-\mathrm{H} ; \mathrm{C}, \mathrm{P}-\mathrm{O}-\mathrm{H}$ bond vibrations of hydrogen bond association; $\mathrm{D}$, coupled vibration of $\mathrm{P}=\mathrm{O}$ bond; $\mathrm{E}$ stretching vibration of $\mathrm{C}-; \mathrm{G}$, stretching vibration of $\mathrm{P}-\mathrm{O} ; \mathrm{H}$, stretching vibration of $\mathrm{P}-\mathrm{O}-\mathrm{C}$; J, O-H vibration; $\mathrm{K}$, vibration of organic acid.

In conclusion, the $\mathrm{P}=\mathrm{O}$ bond in the D2EHPA extractant was not fully coordinated with the zinc ion, and a part of the D2EHPA extractant still existed in the form of a dimer in zinc extraction with the compound additive of alkali and organic acid. Moreover, the presence of alkali and weak acid in the extraction could not only adjust the $\mathrm{pH}$ value, but also improve the saturation capacity of the D2EHPA extractant. As a result, the zinc extraction could be improved by adding a compound additive of alkali and organic acid.

\subsubsection{Demulsification with Associated Additive of Organic Acid and Strong Alkali}

As mentioned above, the emulsification did not occur in zinc extraction with the addition of enough weak acid. Therefore, the emulsification in extraction with the addition of alkali was discussed in this section. FTIR analysis was performed on the emulsion produced in the extraction with the addition of alkali, and the results are displayed in Figure 5. It can be observed that the peaks of P-O-H in the form of hydrogen-bonding association appeared, and it indicates that a new association of $\mathrm{O}-\mathrm{H}$ bond and $\mathrm{P}=\mathrm{O}$ occurred in the emulsion. The new stretch at $3442.41 \mathrm{~cm}^{-1}$ and $3186.79 \mathrm{~cm}^{-1}$ could be assigned to the stretching vibration of $\mathrm{O}-\mathrm{H}$ in water and $\mathrm{O}-\mathrm{H}$ in the form of association, respectively. It indicated that a new $\mathrm{O}-\mathrm{H}$ bond in the form of association existed in the emulsion. Therefore, the $\mathrm{P}=\mathrm{O}$ bond in the emulsion existed in the free state and association state. When the zinc extraction was lower than $100 \%$, the emulsification contained zinc hydroxide. The action of hydroxyl with the reactive bond of D2EHPA-Zn salt caused multi-molecular polymerization in the organic phase. The viscosity of the organic phase increased, resulting in emulsification. However, the $\mathrm{pH}$ value of the extraction solution with the addition of alkali and organic acid was lower than that of the formation of zinc hydroxide, eliminating emulsification in the extraction process. 


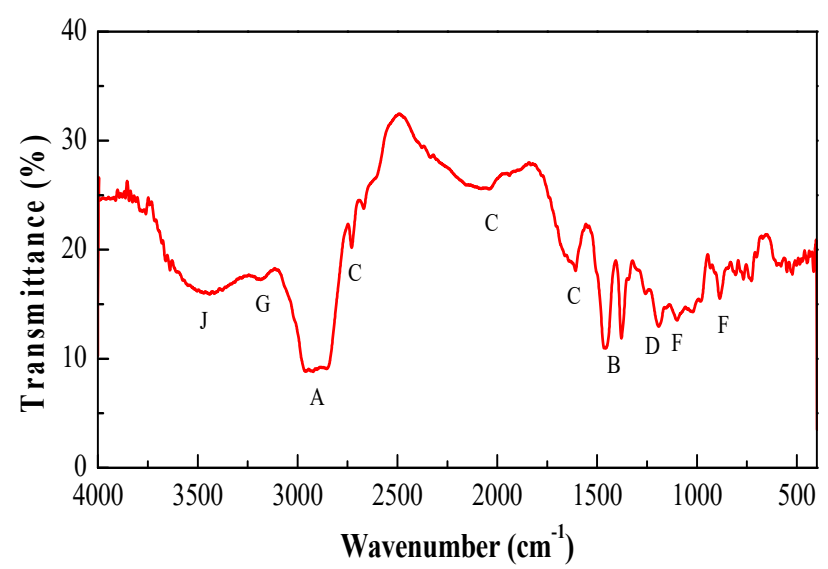

Figure 5. FTIR spectroscopy for an emulsion formed in extraction with the addition of a strong alkali. A, stretching vibration of $\mathrm{C}-\mathrm{H}$; $\mathrm{B}$, bending vibration of $\mathrm{C}-\mathrm{H} ; \mathrm{C}, \mathrm{P}-\mathrm{O}-\mathrm{H}$ bond vibrations of hydrogen bond association; $\mathrm{D}$, coupled vibration of $\mathrm{P}=\mathrm{O}$ bond; $\mathrm{F}$, coupled vibration of $\mathrm{P}-\mathrm{O}-\mathrm{C}$ bond; J, O-H vibration.

\section{Conclusions}

Emulsification was apt to occur in zinc extraction with D2EHPA from zinc solution of high concentration with direct addition of alkali to control solution $\mathrm{pH}$. The saponification pre-treatment of extractant and the addition of sodium salt of organic acid were helpful to demulsification. On this basis, the associated addition of alkali and organic acid applied directly to zinc extraction effectively served to adjust the solution $\mathrm{pH}$ and eliminate emulsification, which ensured a smooth extraction of zinc at high concentrations. Under the condition of $40 \%$ extractant concentration, $104 \mathrm{~mL} / \mathrm{L}$ organic acid, and $80 \mathrm{~g} / \mathrm{L}$ alkali, the zinc extraction favorably reached $99.61 \%$.

The emulsification in the extraction process was mainly due to the formation of zinc hydroxide at sensitively increased $\mathrm{pHs}$ with addition of alkali. With the effect of associated additives of alkali and organic acid, solution $\mathrm{pH}$ could be controlled in the range of 3.0-4.0, which is far below that of the formation of zinc hydroxide, being the main mechanism in improvement of extraction without emulsification.

Author Contributions: T.J., Q.Z. and Y.Y. conceived and designed the experiments; F.M. and K.L. performed the experiments; Y.Y., Q.L., B.X. and F.M. analyzed the data; T.J., Q.L. and B.X. contributed reagents, materials, and analysis tools; Q.Z. and K.L. wrote the paper; T.J. reviewed it before submission. All authors have read and agreed to the published version of the manuscript.

Funding: This work was supported by the National Natural Science foundation of China (No. 51574284), the Hunan Provincial Natural Science Foundation of China (Grant No. 2021JJ40776), the Fundamental Research Funds for the Central Universities of Central South University (No. 202044016), and the Open Sharing Fund for Large-scale Instruments and Equipment of Central South University (CSUZC202129).

Institutional Review Board Statement: Not applicable.

Informed Consent Statement: Not applicable.

Data Availability Statement: The data that supports the findings of this study are available within the paper.

Conflicts of Interest: The authors declare no conflict of interest.

\section{References}

1. Rydberg, J.; Musikas, C.; Chopping, G.R. Introduction to Solvent Extraction. In Principles and Practices of Solvent Extraction; Marcel Dekker Inc.: New York, NY, USA, 1992; pp. 1-17.

2. Owusu, G. Selective ext ractions $\mathrm{Zn}$ and $\mathrm{Cd}$ from $\mathrm{Zn}-\mathrm{Cd}-\mathrm{Co}-\mathrm{Ni}$ sulphaate solution using di-2-ethylhexyl phosphoric acid extractant. Hydrometallurgy 1998, 47, 205-215. [CrossRef] 
3. Kongolo, O.; Mwema, M.D.; Banza, A.N.; Gock, E. Cobalt and zinc recovery from copper sulphate solution by solvent extraction. Miner. Eng. 2003, 16, 1371-1374. [CrossRef]

4. Faubel, W.; Ali, S.A. Separation and purifification of fifission products from process streams of irradiated nuclear fuel. Radiochim. Acta. 1986, 40, 1-5.

5. Zamani, A.A.; Amani, A.A.; Zarabadi, A.S.; Yaftian, M.R. Water soluble crown ethers: Selective masking agents for improving extraction-separation of zinc and lead cations. J. Incl. Phenom. Macro. 2009, 63, 327-334. [CrossRef]

6. Ali, A.M.I.; Ahmad, I.M.; Daoud, J.A. CYANEX 272 for the extraction and recovery of zinc from aqueous waste solution using a mixer-settler unit. Separ. Purif. Technol. 2006, 47, 135-140. [CrossRef]

7. Park, Y.J.; Fray, D.J. Separation of zinc and nickel ions in a strong acid through liquid-liquid extraction. J. Hazard. Mater. 2009, 163, 259-265. [CrossRef] [PubMed]

8. Marcelo, B.M.; Sonia, D.F.R.; Fernando, S.M.; Jeaneth, D.S.B. Selective extraction of zinc(II) over iron(II) from spent hydrochloric acid pickling effluents by liquid-liquid extraction. J. Hazard. Mater. 2008, 150, 669-678.

9. Abdelhamid, M.; Djafer, B. The solvent extraction of zinc, cadmium and chromium from phosphoric acid solutions by tri-nbutyl phosphate in kerosene diluent. Separ. Purif. Technol. 2007, 56, 220-224.

10. Tang, B.; Zhu, Y.C.; Bai, X.M.; Cai, B.; Chen, L.Q.; Zhang, J.H. Study on separation of zinc from iron in waste sulfuric acid pickle liquor by solvent extraction. Min. Metall. Eng. 2003, 5, 47-49. (In Chinese)

11. Yang, Y.; Shi, X.; Li, Q.; Jiang, T.; Wang, W.; Nie, H. Research on Control of pH in Solvent Extraction of Zinc by D2EHPA (P204). In Proceedings of the 19th International Biohydrometallurgy Symposium, Changsha, China, 18-22 September 2011.

12. Luo, F.; Li, D.; Wei, P. Synergistic extraction of zinc(II) and cadmium(II) with mixtures of primary amine N1923 and neutral organophosphorous derivatives. Hydrometallurgy 2004, 3, 31-40. [CrossRef]

13. Keshavarz, A.E.; Moradkhani, D.; Oradkhani, D.; Darvishi, D.; Askari, B.M.; Behnian, C.D. Synergistic effect of MEHPA on co-extraction of zinc and cadmium with DEHPA. Miner. Eng. 2004, 17, 89-92. [CrossRef]

14. Principe, F.; Demopoulos, G.P. Comparative study of iron(III) separation from zinc sulphate-sulphuric acid solutions using the organophosphorus extractants, OPAP and D2EHPA: Part I: Extraction. Hydrometallurgy 2004, 74, 93-102. [CrossRef]

15. Rice, N.M.; Smitth, M.R. The recovery of zinc, cadmium and mercury(II) by solvent extraction. J. Appl. Chem. Biotechnol. 1975, 25, 379-402. [CrossRef]

16. Forrest, C.; Orrest, C.; Hughes, M.A. The separation of Zn from Cu by DEHPA-an equilibrium study. Hydrometallurgy 1978, 3 , 327-342. [CrossRef]

17. Kolarik, Z. Critical evaluation of some equilibrium constants involving acidic organophosphorus extractant. Pure Appl. Chem. 1982, 54, 2593-2674. [CrossRef]

18. Vahidi, E.; Rashchi, F.; Moradkhani, D. Recovery of zinc from an industrial zinc leach residue by solvent extraction using D2EHPA. Miner. Eng. 2009, 22, 204-206. [CrossRef]

19. Pereira, D.D.; Rocha, S.D.; Mansur, M.B. Recovery of zinc sulphate from industrial effluents by liquid-liquid extraction using D2EHPA (di-2-ethylhexyl phosphoric acid). Sep. Purif. Technol. 2007, 53, 89-96. [CrossRef]

20. Chen, S.; Lai, X. A study on extracting zinc out of low acid waste solution form copper leaching process by using D2EHPA agent. Copp. Eng. 2007, 20, 21-23. (In Chinese)

21. Tang, J. Technology and Mechanism of Recovery Zinc from Zn-Bearing Waste Stream by Solvent Extraction. Master's Thesis, Central South University, Changsha, China, 2008.

22. Liu, X. Research on Mechanism and Prevention of Interfacial Emulsion Formation in Copper Solvent Extraction Process. Ph.D. Thesis, Central South University, Changsha, China, 2001.

23. Brown, E.N.; White, S.R.; Sottos, N.R. Microcapsule induced toughening in a self-healing polymer composite. J. Mater. Sci. 2004, 39, 1703-1710. [CrossRef]

24. Biniak, S.; Szymanski, G.; Siedlewski, J.; Światkowski, A. The characterization of activated carbons with oxygen and nitrogen surface groups. Carbon 1997, 35, 1799-1810. [CrossRef]

25. Shi, X. Technology and Mechanism on Solvent Extraction of Zinc from High Concentration Zinc Solution by P204. Master's Thesis, Central South University, Changsha, China, 2011. 